\title{
University-Community Partnerships: Managing Expectations and Leadership
}

\author{
ALEXIS GREGORY \\ Mississippi State University
}

\begin{abstract}
"[A] troubled universe can no longer afford the luxury of pursuits confined to an ivory tower...[S]cholarship has to prove its worth not on its own terms, but by service to the nation and the world." Oscar Handlin ${ }^{1}$
\end{abstract}

Architecture programs have worked with community partners for some time, and the benefits to the students and university have been proven by various studies. ${ }^{2}$ However, the community partner does not always benefit, which creates a lack of trust, and lack of interest on the part of the community partners to working with universities. ${ }^{3}$ This relates to the typical "Ivory Tower" problem that universities face generally, and the lack of a reciprocal relationship with a community partner just exacerbates the issue. This paper posits that both universities, specifically architecture programs, and community partners need to start their relationships with managed expectations of what the collaboration will create, how long it will take to reach project goals, and how the leadership structure will evolve over time. This will help to instill a relationship of trust that can create egalitarian partnerships to dispel the image of the "Ivory Tower." 4 Once trust is achieved both architecture students and architecture educators can lead community partners into leadership positions of their own to take charge of the public interest design projects that are created together.

\section{INTRODUCTION}

Benefits and Challenges to Community Engagement

Our university is a land-grant university that embraces community engagement, which helps to support the research, teaching, and service of faculty that would like to utilize community engagement as a part of their job. Due to this the university defines multiple terms in relation to community engagement to help faculty, students, and community partners begin to speak the same language when it comes to collaboration. Specifically, "community engagement" is defined as "...collaboration between Mississippi State University and partnering communities for the mutually beneficial exchange of knowledge and resources in a context of partnership and reciprocity." 5 The university is also only one of only 361 institutions in the U.S. that have received a Community Engagement Classification by the Carnegie Foundation. This classification signifies "colleges and universities with an institutional focus on community engagement..." that elected to apply for classification to document and reinforce their commitment to community engagement. ${ }^{6}$ This public information and outreach is meant to create openness and trust as to our university's approach to community engagement.

Trust is an important factor in the development of universitycommunity partnerships, and as De La Garza and Kuri note, some community partners do not trust the university from the start. They had a community partner who consistently questioned their motives and wondered why anyone would want to work with their organization. ${ }^{7}$ This author also had varying levels of trust from community partners, but in relation to the different faculty, students, and professionals involved in the projects. Trust is one of the many benefits and challenges of university-community engagement projects that can lead to removing the image of the "Ivory Tower" from the minds of the community. Additional challenges include barriers such as the practical concerns with planning and communication during a project, as well as lack of skills on both the part of the community partner and university members (faculty and students). Most noticeable to the author were the attitudinal barriers of the community partners she has worked with. ${ }^{8}$ These ranged from disinterest in working equally with the university team to outright challenges and undermining of the university team. Benefits include improved teaching, better university-community relationships, and the empowerment of the community. Klein et al. have promoted the development of "knowledge co-generation" and "knowledge exchange" as important benefits that help both the university and community partner. ${ }^{9}$ This is also important to what is called the "Third Mission" of the university: Service. Yet, service in a university setting is rarely seen as service to the community, but instead service to the university. Boyer noted in The Scholarship of Engagement that service is not as important to tenure as research and teaching. Even in universities such as ours with a Community Engagement Classification and access to Extension services based on the land-grant mission it is not easy to get institutional support for service outside of the university. This has created the continued deterioration in trust that the public has in colleges and universities. More than twenty years ago Boyer asserted that the "scholarship of engagement" needed to be reaffirmed to gain that trust back from the public, and his statement is still valid even today. ${ }^{10}$

The creation of a university-community partnership (UCP) is far more complicated than some realize. This tendency to see the UCP as a simple drop-in kind of project leads to the mistrust that community partners have in university programs. Strier discusses how building these partnerships "...is a 


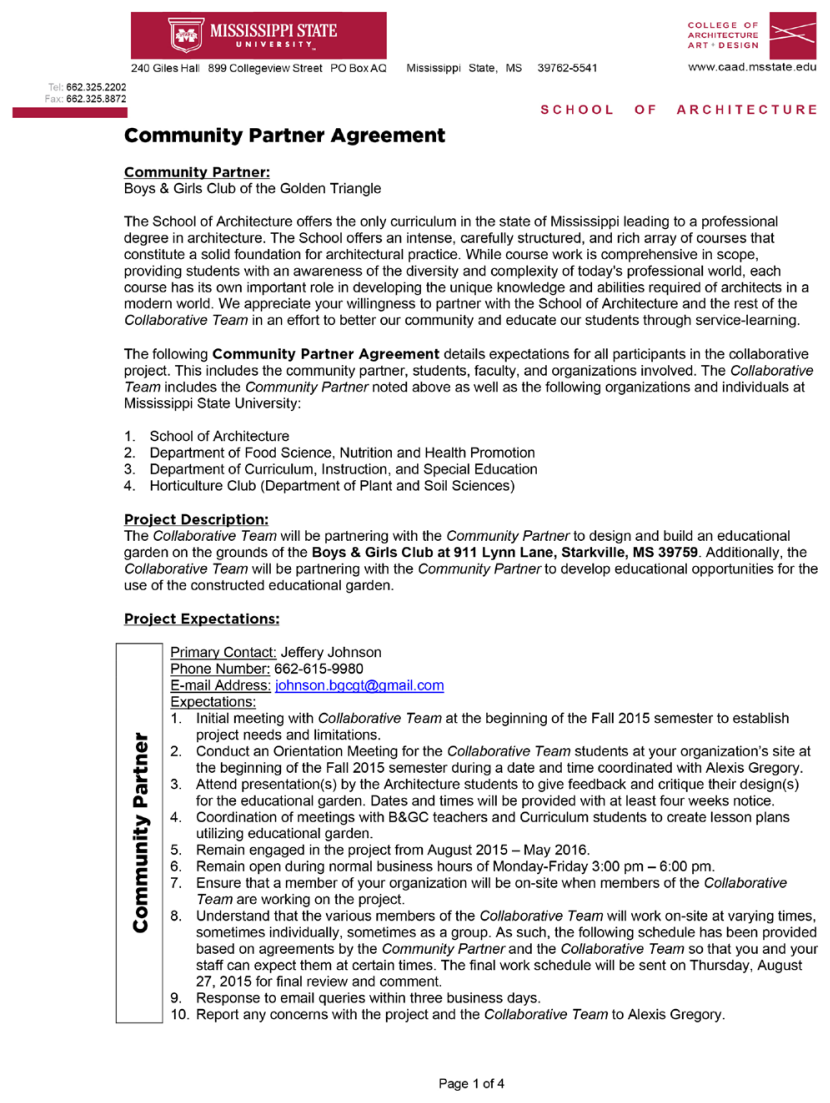

Figure 1: Community Partner Agreement (by author).

highly complex process which involved multiple tensions and conflicts." These partnerships need a lot of maintenance, as with any project or relationship. Yet most faculty and students focus on the university side of the project attending mainly to student outcomes and faculty research. The development of a strong partnership requires excellent organizational and communication skills, but still may need to change and evolve with the project. There will be ample opportunities for conflict resolution, but this may require more time and resources than all parties can provide. ${ }^{11} 12$ This is why managing expectations for the project is such an important part of the leadership aspect from the point of the university partner (faculty and students). The author has approached this challenge with the creation of a Community Partner Agreement, which is an informal agreement to be used to outline expectations for all parties involved. (Figure 1) The intent was to create a framework, before the project even began, as to how to proceed so that both the university and the community partner understood their roles and responsibilities. Nevertheless, misunderstandings and miscommunications still happened.

Additionally, the creation of an egalitarian approach to university-community partnerships is an important way to establish trust. The idea of "mutual knowledge" asserted by Giddeon can be used to dispel the "myth of the ivory tower" and create a reciprocal relationship between the partners. ${ }^{13}$ The use of

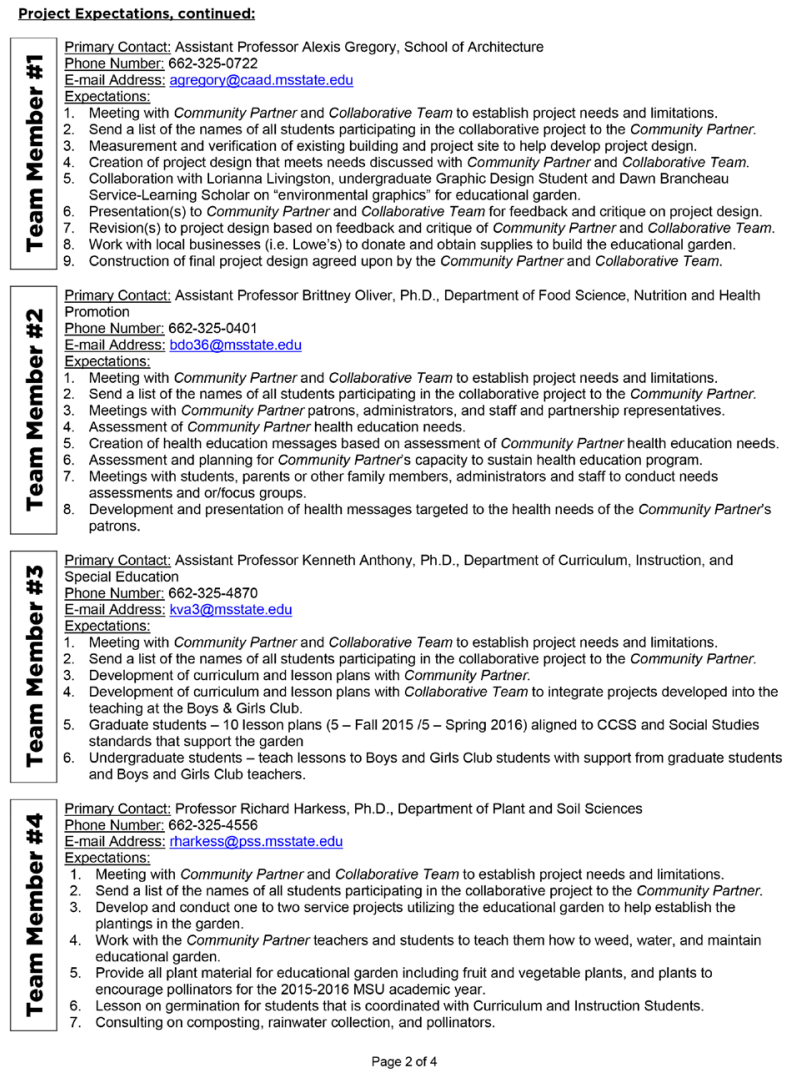

egalitarianism to abandon hierarchies is necessary to prevent an exclusionary environment that discourages the community partner from participating. This makes the project more accessible, and therefore more reflective of all partners involved, not just the faculty and students. ${ }^{14} 1516$ University faculty and students can show leadership by creating this egalitarian environment so that community partners not only have more faith in their own ability to lead, but in the abilities of others. The author experienced this issue with a community partner who would not trust the other faculty in the project from other departments. Moreover, there was confusion in the community partner leadership as to who was to make decisions involving the project. Empowering the community partner is a sign of true leadership and is required to make sure that projects are sustained once the faculty and students move on. ${ }^{17}$

\section{Empowering Through Leadership}

"A better definition in relation to spatial agency is that the agent is one who effects change through the empowerment of others, allowing them to engage in their spatial environments in ways previously unknown or unavailable to them, opening up new freedoms and potentials as a result of reconfigured social space." Spatial Agency: Other Ways of Doing Architecture ${ }^{18}$ 
It may seem contradictory to state that leadership is empowering others to take charge of a project, but faculty constantly do this through the teaching and mentoring of students. Faculty, and the students they are teaching, have the abilities to study the organizational culture of a community partner in order to propose a project structure that will allow the project to be led and maintained by that community partner. These proposals can be part of the Community Partner Agreement so that the community partner understands what is being expected of them so that they can take over the long-term maintenance of the project. However, there are barriers to empowerment as well that the faculty and students must deal with to make the project successful.

The "Partnership Framework" that is created by a Community Partner Agreement can help empower, but failure is still not inevitable which can be especially frustrating for all partners because of all the time and effort involved. Faculty must look for three components that might be missing from servicelearning projects that could lead to this failure. First, the course itself must have learning objectives that are appropriate to the university-community partnership. ${ }^{19}$ If this is not the case then the faculty and students will not be focused on the "learning" aspect of the service-learning project and will lose sight of the goals. Second, the planning of the project is an obvious element, however, the assessment of the project, whether over time or at the end of the project, is often overlooked. Post-occupancy evaluations and community partner surveys will help to assess the successes and failures of the project. Reflections by the students are also an important part of the assessment, as are observations and reflections by the faculty over the course of the project. Lastly, the establishment of a successful partnership with the community, not just the community partner, is paramount. The community should be informed about the collaboration and how it is working to improve the community, not just the university successes. ${ }^{20}$

Once these three components are established in a universitycommunity partnership there may still be areas where failure can occur. Reflection and assessment of student and faculty impressions of the project are discussed above, but reflections from the community partner are often neglected and even left out completely. The review of the literature shows a very large disconnect between data collection from the university perspective and from the community perspective. ${ }^{21}$ Oftentimes the main staff in a community partner will be excluded from data collection even though they are the primary contacts on a daily basis, while only the administrators are surveyed. ${ }^{22}$ Also, faculty and students are known to have very high hopes for university-community partnerships, which can put a strain on the community partner due to unrealistic expectations. Architecture studios, with their generally high expectations and workload, tend to exacerbate this issue and must be addressed. Community partners are not always prepared for the workload and schedule that an architecture studio typically entails.
Conducting an in-depth study and volunteering with the community partner to develop a better understanding of the knowledge, strengths, weaknesses, and abilities of the community partner can remedy this. ${ }^{23} 24$ This will help to eliminate the exclusion of diverse experiences and perspectives since many of the staff in the community partners will have different experiences and education levels than the students and faculty. Something of this depth may be needed before a partnership even begins to help with the appropriate development of the course objectives, planning, and assessments discussed above. Added threats to the partnership include staff turnover, which the author has experienced in several university community partnerships, and communication issues. Due to this faculty and students must be flexible and be able to adapt their courses to accommodate staffing changes and communication changes on a regular basis. ${ }^{25}$

\section{$\underline{\text { Student Learning Experiences Develop Future Leaders }}$}

While the student learning experience tends to usurp the experience of the community partner, it can be maintained, and even heightened, by a successful partnership that is egalitarian in format. Architecture education tends to focus on hypothetical design projects due to the time limitations of the academic semester and the complexity of real-world architectural design. Collaborations with a community partner allow the students the opportunity to work with a real client, and to show the application of the theoretical ideas they learn in other classes. ${ }^{26}$ The collaborative nature of the projects also allow for the inclusion of other departments and professions in the university-community partnerships. The author has worked with faculty from departments such as the Department of Philosophy and Religion, the Department of Food Science, Nutrition, and Health Promotion, and the Department of Special Education and Curriculum. Professions that have collaborated on university-community partnerships include structural engineers, landscape architects, farmers, contractors, and local politicians.

The students also learn to work with people who come from different socio-economic backgrounds, different religious backgrounds, and different races. Several projects that the author has coordinated exposed students to working with children, which is not something that all architecture students get the opportunity to do. Exposing students to a large crosssection of potential clients and partners gives them a unique opportunity to better prepare to practice architecture for, and with, the public in the future. ${ }^{27}$ Discussion of the students' experiences is very important, ${ }^{28}$ which is why reflections are a key factor in service-learning along with reciprocity. ${ }^{29}$ Students tend to think that they are there to support the community partner, to give them something because they are in need. However, students must be taught, and faculty must remember, that community members are partners, not a charity case that has no knowledge, or say in how a project 
should be created and developed. ${ }^{30}$ Volunteering is a great start to get students engaged in the community, but since it is not a true partnership with egalitarian features the students think that all community engagement is them giving to someone in need with no reciprocal relationship. ${ }^{31}$ By linking the courses to student reflections and course readings on theory related to community engagement and reciprocity students are able to understand the complex and important relationship of university-community partnerships. ${ }^{32}$

\section{PROJECT DETAILS}

The author approached the community partner after reading about a need they had to expand and create programming for their community garden. The project was developed without input from the Unit Director because he was leaving and no information was given as to who the new Unit Director would be. However, the new Unit Director was very supportive and enthusiastic when the author approached him with a basic project framework. The next step was the development of the overall educational garden and the aspects related to other departments and fields. The author recruited faculty from the Department of Plant and Soil Sciences, Department of Art - Graphic Design Concentration, Department of Philosophy and Religion, the Department of Food Science, Nutrition, and Health Promotion, and the Department of Special Education and Curriculum. This diverse collection of faculty was intended to work together to create programming for the educational garden once it was designed and constructed by the architecture design studio. All faculty and the Unit Director were invited to student design presentations to critique the work and give feedback not only on the design aspects, but also on the durability, usability, and function in regards to the garden aspect. (Figure 2). The students respected and utilized the information both from the various faculty, and from the Unit Director. Once the project was complete the faculty from other departments created programming and curriculum to integrate with the requirements of the community partner. However, the current Unit Director left at this important juncture and the new Unit Director was not as engaged in the project.

Based on this staffing change the programming and curriculum was no longer supported and the collaborative team of faculty and students attempted to maintain the project. The faculty from Health Promotion interviewed the staff, both general staff and administrators, to gauge their interest and knowledge about the project. The data gathered showed what the collaborative team of faculty had expected based on their experiences; the staff wanted nothing to do with the project. Three themes were identified by the Health Promotion faculty including relevance and value of the project, internal resources and barriers to the project, and external factors. Comments from the staff are noted below:

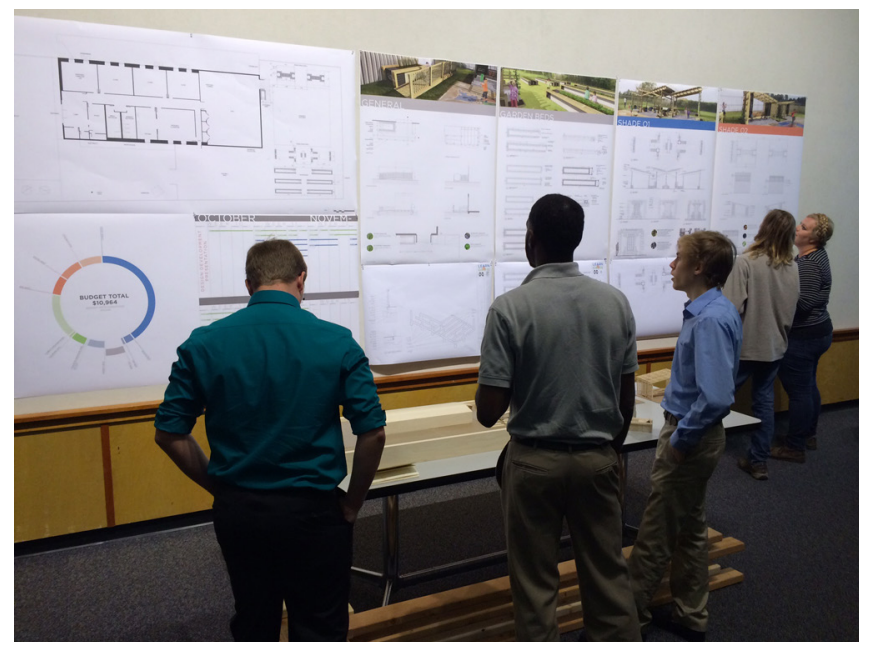

Figure 2: Presenting to the Director of a non-profit for children (photo by author)

\section{$\underline{\text { Relevance and Value }}$}

- "I would like ... to see out of this garden project ... that children get the nutritional aspect, but I would like them to ... see how it can be cost-effective to them."

- "I think they are learning and ... they are getting exposed to something different, something new ..."

\section{$\underline{\text { Internal Resources and Barriers }}$}

- “... we have a junior staff program ... and if we had kids ... that have a particular interest in gardening and outdoor life, we could push to those junior staff to ... maintain the garden."

- "But just to say that we can add it on, tack it on to the other programs that we are running, that have to be run that day, it's kind of hard to say that we could do that."

- "So sometimes we are so bound to those schedules that doing things that ... could really be helpful ... we can't find a way to fit it and plug it in; it just can be complicated. So I would say time is also a factor there."

- "... when it comes to gardening to be honest, I really don't know that much about it."

\section{External Factors}

- "... it is curriculum that people who actually know what they're talking about ... [are] giving to me; I think it would be, the chances of being able to do it are way higher."

- "I mean the system that seems to be in place, that ... you're always going to have students and ... they could always have a part of their coursework [to] be coming and working at the ... garden." 33 
Despite the lack of interest from the staff with the community partner, the university students involved in the project were much more enthusiastic.

\section{Selected Student Comments}

- "Great experience this semester. It was good to have an actual client and get some construction experience."

- “Doing a service-learning project was a great idea..."

- "Great enthusiasm and very helpful."

- "Enjoyed the studio organization that resembled a firm. It was fun working directly with the client. I enjoyed my role in the studio project."

- "She did a good job encouraging design..."

- "Professor Gregory has been a fantastic teacher, not only caring about what students produce but also the student themselves. She is considerate, accommodating, understanding and fair. She expects results from her students, and we are motivated by her to push ourselves and to do our best, better than we thought possible."

- "This was a good project..."

- "It was nice to actually have interactions with a client."

- "It was fun working with client."

- "...I had fun and learned a lot."

- "Great class and I loved I got to help finish the project from last semester. Construction experience is important and Professor Gregory is an honest as well as competent teacher. She definitely knows her stuff. I also had a blast!"

- “Great professor!!!”

- "Enjoyed the hands on experience."

Due to the community partner's resistance to be an equal partner in the project several faculty withdrew from the project. Many were unable to gather research and data on the project, or even get the Unit Director to return phone calls and emails. Unfortunately this was an issue that had been brought up to the author when she was doing research on the project before approaching the community partner. Despite these warnings, the author felt that she could overcome these past issues through the Community Partner Agreement, excellent organization, and communication. That did not end up being the case. The few faculty that were left have been attempting to work with the Director of the regional community partner, and the Unit Director. Various proposals on how to integrate the educational garden into the required programming of the community partner have been submitted, with limited success. Currently there is a new Unit Director who has been a staff member, volunteer in the educational garden, and is much more enthusiastic about the project. Furthermore, the local Master Gardener Volunteers have approached the community partner to work with the children in the garden despite past reluctance to be involved.

\section{RESULTS}

Turnover

As noted in both the literature review, and the project details, staff turnover with the community partner has been a big issue. Not only have there been four Unit Directors over the two years of the project, there has also been staff turnover of the general staff who ideally would coordinate the programming for the educational garden. The turnover of university students has also been an issue as the collective knowledge about the project over the past two years is not always passed on and most often lost. The faculty turnover has also been hard because the project was initially designed as a collaborative project with six faculty. Currently, only the author is participating in the project. Lack of investment by the community partner has been a large deterrent to keeping the faculty engaged as they are unable to justify their time and involvement when they are unable to glean knowledge and data from the project to help with their research and teaching.

\section{Funding}

All faculty are experienced in the struggle to fund research and keep projects afloat based on university funding and the economic swings. However, this project was built through a collection of grants, crowd funding, and material donations. But to keep the project going the community partner has been very resistant to even provide the staff time and resources to the project. The author has been to board meetings where the director of the board assured the other board members that "they are paying for this all by themselves." Which is concerning to the author and the collaborative faculty as the community partner is not seeing any reason to be equally engaged in the project. The author had been working with one of the collaborative faculty, and her students, to work with the community partner to develop a staff-training guide to empower the community partner and the staff to take over the project. The guide would have included the lessons and programming that had already been developed by the faculty from the Department of Special Education and Curriculum, but the Director and Unit Director did not return phone calls or emails with a new Community Partner Agreement to allow this collaboration to take place.

\section{Communication}

The author has found that there were various approaches to communication with various the different Unit Directors, despite the Community Partner Agreement outlining the requirements for communications. Even the most supportive Unit Director was so overwhelmed by his job with the 
community partner that the author did not find out about the Director and Board of the community partner until her class and the collaborative team were well into the project design. Some Unit Directors were very responsive and interested in project, some were not, which put up a lot of barriers. Even the Master Gardener Volunteers had communication problems with the past Unit Director despite her asking them to come work with the children in the garden. The Director also varies in her levels of communication so the author and other collaborative team members are often confused about who is making what decisions about the project. The good news is that the new Unit Director is excellent at communication and seems to be very interested in pursing the project further.

\section{Community Partner Investment}

Overall, the community partner has resisted any involvement in the development and maintenance of the project over the past two years. This has come both from general staff and administrative staff. The author and various faculty have reached out many times to try to overcome this issue as the community partner has admitted that they need the project and programming and that they struggle with engaging the staff and students in the project. Getting parents involved has also been a struggle, but one that the community partner has with all issues related to their work. Luckily the current Unit Director is using Facebook, which the parents are engaged in, to communicate not just about the general programs but also about this project specifically. Hopefully this new leadership will move past the barriers we have been experiencing and embrace the collaborative nature of this partnership.

\section{CONCLUSION}

This particular project has been a unique learning experience in how to manage expectations when working with a community partner. Architects tend to design projects and leave them for the user to maintain. Community partnerships are longer-term relationships that need more effort and longterm commitment, which is a valuable lesson for students to learn. Based on this the author recommends several things to establish a successful university-community partnership. First, make sure not just to educate students on universitycommunity partnerships and the responsibilities of all, but also the community partner. This is because the community partner may not understand the commitment they will be required to undertake. This leads to the Community Partnership Agreement where all roles and expectations are clearly defined. Continued work on communication is required and all parties must be committed to this or nothing will work. Communication may also need to be adjusted and each year a new Community Partnership Agreement can address this. Lastly, create short and long-term goals to help focus the project and allow for planning from all team members from faculty to community partner to other involved groups like volunteers. Likewise, make sure to include the community partner in project planning to aid in the clarity and durability of the project. This will be time intensive, so be sure to plan accordingly for the project development, from approaching the community partner, establishing trust, developing the project, to implementing and maintaining the project. Assess the various parts and team members on a regular basis, and integrate this into the project. This includes yearly assessments of the students, faculty, team members, and staff and administrators of the community partner, who tend to be forgotten, but are important not to ignore to allow for a continued open and successful relationship for the future. Leadership is not easy, and comes with many responsibilities, but teaching students how to work with community partners and to manage their expectations is an excellent way to create future leaders by engaging in important work that might not otherwise be done.

\section{ENDNOTES}

1 Boyer, Ernest L. "The Scholarship of Engagement." Journal of Higher Education Outreach and Engagement, vol. 20, no. 1, 2016, pp. 27.

2 Gregory, Alexis and April Heiselt, "Reflecting on Service-Learning in Architecture: Increasing the Academic Relevance of Public Interest Design Projects." GLOBALIZING ARCHITECTURE/Flows and Disruptions - Proceedings from the 102nd ACSA Annual Meeting, Spring 2014, pp. 404-410.

3 Strier, Roni. "The construction of university-community partnerships: entangled perspectives," pp. 83.

4 Tal, Rinat Botbol, Tovi Fenster, and Tal Kulka. "Academy-Community Partnerships: Challenges and Changes in Israeli Urban Regeneration Projects." Journal of Higher Education Outreach and Engagement, vol. 19, no. 3, 2015, pp. 65-66.

5 Team, ITS Web Development. "About Us » What Is Service-Learning?" About - What Is Service-Learning? - CCEL , 4 Aug. 2017, www.servicelearning.edu/ about/whatis/.

6 Carnegie Selects Colleges and Universities for 2015 Community Engagement Classification." Carnegie Foundation for the Advancement of Teaching, 7 Jan. 2015, www.carnegiefoundation.org/newsroom/news-releases/carnegieselects-colleges-universities-2015-community-engagement-classification/.

7 De La Garza, Tammy Oberg, and Lissette Moreno Kuri. "Building Strong Community Partnerships: Equal Voice and Mutual Benefits." Journal of Latinos and Education, vol. 13, 2014, pp. 123.

8 Klein, Phil, et al. "Dismantling the Ivory Tower: Engaging Geographers in University-Community Partnerships." Journal of Geography in Higher Education, vol. 35, no. 3, Aug. 2011, pp. 437-439.

9 Ibid, 427-436

10 Boyer, Ernest L. "The Scholarship of Engagement." Journal of Higher Education Outreach and Engagement, vol. 20, no. 1, 2016, pp. 15, 18.

11 Strier, Roni. "Fields of paradox: university-community partnerships." Higher Education, vol. 68, no. 2, 2014, pp. 157-159.

12 Strier, Roni. "The construction of university-community partnerships: entangled perspectives." Higher Education, vol. 62, no. 1, Jul. 2011, pp. 83.

13 Awan, Nishat, et al. Spatial Agency: Other Ways of Doing Architecture. Routledge, 2011, 32

14 Ibid, 159.

15 Strier, Roni and Dorit Shechter. "Visualizing access: knowledge development in university-community partnerships." Higher Education, vol. 71, no. 3, Mar. 2016, pp. 343-359.

16 Strier, Roni. "The construction of university-community partnerships: entangled perspectives," pp. 83.

17 Suarez-Balcazar, Mansha Parven Mirza and Anne Marie Witchger Hansen. "Unpacking University-Community Partnerships to Advance Scholarship of Practice." Occupational Therapy in Health Care, vol. 29, no. 4, pp. 375.

18 Awan, Nishat, et al. 32

19 McDonald, James and Lynn A. Dominquez. "Developing University and Community Partnerships: A Critical Piece of Successful Service Learning." Journal of College Science Teaching, vol. 44, no. 3, 2015, 53.

20 McDonald, James and Lynn A. Dominquez, 52. 
21 Suarez-Balcazar, Mansha Parven Mirza and Anne Marie Witchger Hansen. 371.

22 Ibid, 380

23 Ibid, 373-376.

24 McDonald, James and Lynn A. Dominquez. 53-54.

25 Ibid, 378-390.

26 Tal, Rinat Botbol, Tovi Fenster, and Tal Kulka, 63.

27 Ibid, 66.

28 Ibid, 67.

29 Schuman, A. (2006). Introduction: The Pedagogy of Engagement. From Studio to the Streets: Service-Learning in Planning and Architecture. Sterling, VA: Stylus. 1-15.

$30 \mathrm{lbid}, 81$.

31 Corporation for National and Community Service, Office of Research and Policy Development. (2010, June). Volunteering in America 2010: National, state, and city information. Washington, DC.

32 Tal, Rinat Botbol, Tovi Fenster, and Tal Kulka, 81-82.

33 Oliver, Brittney. "It's kind of hard to say that we could do that': Organizational Perceptions of Implementing an Educational Garden." A Disparities Paradox? Food Insecurity \& Obesity Among Vulnerable Populations, Poster Presentation, Jackson, Mississippi, July 17-18, 2017. 